\title{
INFLUÊNCIA DA NEBULOSIDADE NA ATENUAÇÃO ATMOSFÉRICA NA CIDADE DE PELOTAS-RS: ESTUDO DE CASO
}

\author{
Rodrigo da Silva Pereira ${ }^{1, *}$, André Becker Nunes ${ }^{1}$ \\ ${ }^{1}$ UFPEL/PPGMET - Pelotas/RS \\ *ps_drigo@yahoo.com.br
}

\section{RESUMO}

No trabalho, foi analisada a atenuação atmosférica na cidade de Pelotas nos dias 20 e 27 de fevereiro e 21 e 22 de junho de 2013, por meio do cálculo da transmitância. Os resultados mostraram que a radiação solar incidente na superfície foi atenuada pela a absorção dos gases e espalhamento das partículas suspensas na atmosfera. Mas, a grande quantidade de nuvens foi primordial para diminuir a transmitância da atmosfera, provocando uma forte atenuação, aproximadamente $81 \%$.

Palavras-chave: Transmitância, Caminho Ótico, Lei de Beer.

\begin{abstract}
In the study we analyzed the atmospheric attenuation in Pelotas on 20 and 27 February and 21 and 22 June 2013, by calculating the transmittance. The results showed that in both days the incident solar radiation on the surface was attenuated by absorption and scattering of the gas particles suspended in the atmosphere. But, a lot of clouds was paramount to decrease the transmittance of the atmosphere, causing a strong attenuation approximately $81 \%$. Keywords: Transmittance, Optical path, Beer's law.

\section{INTRODUÇÃO}

Ao deslocar-se pela atmosfera, a radiação solar está sujeita a várias transformações devido à absorção, reflexão e espalhamento das partículas. O topo das nuvens é o mais importante refletor, sendo esta reflexão fortemente ligada a quão espessa é a nuvem ou mesmo a camadas de nuvens presente na atmosfera. $\mathrm{O}$ objeto do trabalho foi verificar a atenuação atmosférica com céu encoberto e com céu claro em Pelotas-RS, utilizando uma das formas da Lei de Beer.
\end{abstract}




\section{DADOS E METODOLOGIA}

Os dados de nebulosidade (N), umidade relativa (UR) e radiação na superfície, utilizados para realizar o trabalho, foram extraídos dos boletins agroclimalógicos (fevereiro e junho de 2013) da Estação Agroclimatológica de Pelotas-RS (EAP) (latitude: 31 52'00” S; longitude: 52²1' 24" W; altitude: 13,24 m). Foram determinadas as variáveis: declinação solar $(\delta)$ (Iqbal, 1983); ângulo horário (H) (Liou, 2002); e radiação no topo da atmosfera (Q) (Petty, 2006) para os dias estudados, utilizando as equações:

$$
\delta=23.45 \sin ((360 / 365)(284+\mathrm{n}))
$$

Onde n é numero de dia Juliano (variando de 1 a 365, sendo o dia Juliano igual 1 para o primeiro dia do mês de janeiro).

$$
\mathrm{H}=\arccos (-\tan \varphi \cdot \tan \delta)
$$

Sendo $\phi$ a latitude, e

$$
\mathrm{Q} \cong \frac{\mathrm{S}_{0}}{\pi}\left(\frac{\overline{\mathrm{D}_{\mathrm{S}}}}{\mathrm{D}_{\mathrm{S}}}\right)^{2}[\mathrm{H} \sin \varphi \sin \delta+\cos \varphi \cos \delta \sin \mathrm{H}]
$$

Aqui, $\mathrm{S}_{0}\left(1370 \mathrm{~W} / \mathrm{m}^{2}\right)$ é o fluxo solar médio para uma distância média entre Sol e a Terra ( $\left.\overline{D_{s}}\right),\left(D_{s}\right)$ a distância entre Sol e Terra para um dia Juliano qualquer, e H representa a metade do fotoperíodo (em radianos). A atenuação foi determinada através de uma das formas da lei de Beer, em função da transmitância $(t)$ e do caminho ótico $(\tau)$ (Petty, 2006), onde a energia não transmitida é atenuada. Assim, a transmitância é dada por:

$$
t=\frac{I}{I_{0}}=\exp \left(\frac{-\tau}{\mu}\right)
$$

$\mathrm{E}$

$$
\tau=-\ln t
$$

Sendo $\mathrm{I}\left(\mathrm{W} / \mathrm{m}^{2}\right)$, a radiação medida na $\mathrm{EAP}, \mathrm{I}_{0}=\mathrm{Q}\left(\mathrm{W} / \mathrm{m}^{2}\right)$ a radiação no topo da camada atmosférica e $\mu=|\cos \theta|$, onde $\theta$ é o ângulo zenital, que pode ser aproximado por: 


$$
\cos \theta=\operatorname{sen} \varphi \operatorname{sen} \delta+\cos \varphi \cos \delta \cosh
$$

Onde $h$ é o ângulo horário.

Tabela 1. Dados da EAP e resultados obtidos através da metodologia adotada nesse estudo:

\begin{tabular}{|c|c|c|c|c|}
\hline Dia & $20 / 02 / 13$ & $27 / 02 / 13$ & $21 / 06 / 13$ & $22 / 06 / 13$ \\
\hline $\begin{array}{c}\text { Nebulosidade (décimos } \\
\text { de céu) }\end{array}$ & $\begin{array}{c}10 \\
\text { (céu encoberto) }\end{array}$ & $\begin{array}{c}2 \\
\text { (céu claro) }\end{array}$ & $\begin{array}{c}10 \\
\text { (céu encoberto) }\end{array}$ & $\begin{array}{c}1 \\
\text { (céu claro) }\end{array}$ \\
\hline UR (\%) & 94,8 & 74,5 & 99,5 & 68,3 \\
\hline$Q\left(w / m^{2}\right)$ & 447,7085 & 432,0661 & 201,4412 & 201,3919 \\
\hline $\begin{array}{c}\text { Radiação na Superfície } \\
\qquad\left(\mathrm{w} / \mathrm{m}^{2}\right)\end{array}$ & 84,39 & 277,905 & 37,83 & 135,315 \\
\hline Transmitância (\%) & 18,89 & 64,32 & 18,78 & 67,19 \\
\hline Caminho ótico & 1,6665 & 0,4413 & 1,6724 & 0,3976 \\
\hline Atenuação (\%) & 81,11 & 35,68 & 81,22 & 32,81 \\
\hline Atenuação (w/m²) & 363,3185 & 154,1611 & 163,6112 & 66,0769 \\
\hline
\end{tabular}

\section{RESULTADOS E DISCUSSÕES}

Os resultados apresentados na tabela 1 indicam que para condição de céu encoberto, a radiação na estação comparada à recebida no topo da atmosfera sofreu uma grande atenuação em função da alta umidade e da grande quantidade de nuvens. Além da disso, uma baixa transmitância da energia solar e uma maior extinção dessa energia quando atravessou o interior da atmosfera, o que culminou num caminho ótico maior. Nos dias desanuviados e com menor teor de umidade, grande parte da irradiação solar incidente no topo da atmosfera atingiu a superfície (EAP), pois a transmitância foi aproximadamente 4 vezes maior. Ressalta-se que no mês de fevereiro a maior umidade no ar explica a atenuação de cerca de 3\% maior. Pois, como pode ser visto pelas Eqs. 4 e 6 , a transmitância é função da declinação, sendo maior no verão. 


\section{CONCLUSÃO}

A absorção pelos gases atmosféricos e o espalhamento pelas partículas suspensas na atmosfera causam um decaimento na intensidade do feixe de radiação ao atravessá-la. Porém, a grande quantidade de nebulosidade foi fundamental na transmitância da atmosfera calculada neste trabalho, influenciando fortemente na atenuação (81\%).

\section{AGRADECIMENTOS}

O primeiro autor agradece a CAPES pela bolsa de mestrado.

\section{REFERÊNCIAS}

IQBAL, Muhammad. An Introduction to Solar Radiation, Academic Press Canada, Toronto, 390 p., 1983.

LIOU, K.N. An Introduction to Atmospheric Radiation. Academic Press, New York.

PETTY, G. W. A First Course In Atmospheric Radiation. Sundog Publ. Madson, Wisconsin, 452 p. 2006. 